the proper "appraisement of the malaria situation" becomes of great importance, and an excellent chapter on this aspect of the case is given. There are chapters also on the part played by the different malaria parasites themselves, and the role of immunity in man in the epidemiology of the disease, also a chapter on treatment in theory and practice, and an extremely interesting section on the strategy of malaria control and various fundamental lines of attack upon the disease.

Very seldom are the facts about disease so pleasantly and easily written about as in this volume, which is quite unique of its kind. Nowhere else will the reader obtain so easily the spirit of modern malaria research in its application to prevention.

S. R. C.

\title{
The Case for Buchan
}

Buchan's Days :

a Modern Guide to Weather Wisdom. By E. L. Hawke. Pp. 231. (London: Lovat Dickson and Thompson, Ltd., 1937.) 5s. net.

A LEXANDER BUCHAN, secretary of the A Scottish Meteorological Society from 1860 until his death in 1907, was esteemed in his lifetime as a worthy man, an able secretary and a tireless investigator. He wrote two excellent books on meteorology, but it is probably true to say that, until a few years ago, his name was almost unknown outside the circle of meteorological devotees. Now, strangely enough, his name is probably the first that would occur to ninety-nine out of a hundred examination candidates who were asked, in a 'general knowledge' paper, to state the name of a distinguished meteorologist, dead or alive.

Buchan's posthumous fame has been acquired as a result of his researches on the irregularities in the annual march of temperature, as revealed by daily averages of temperature at certain Scottish stations. When such daily averages are plotted, it is found that the resulting graph differs very materially from a smooth curve. The temperature does not rise steadily from a minimum in winter to a maximum in summer and then fall steadily again to the winter minimum. On the contrary, a series of humps and hollows is fornd, indicating that a steady rise or fall is not, on the average, maintained for more than a few days at a time. Buchan satisfied himself that certain of these humps and hollows were due to a tendency for spells of relatively warm or cold weather to recur around definite dates. Buchan's "warm periods" and "cold periods" have thus kept alive the name of the worthy Scottish meteorologist.

Since Buchan's death, there has been much controversy as to whether these "periods" are a real and permanent climatic feature of our area. Participants in the controversy have not always taken the trouble to refer to Buchan's original papers, consequently, much of what has been written is irrelevant to the issue. Mr. E. L. Hawke has done a useful service in giving a fair and clear summary of the original papers. His commentary upon the papers is not very likely, however, to win over many adherents to what we may call the 'Buchan doctrine'. He directs our attention to the resounding "successes" scored, for example, in the famous frosts of February 1917 and February 1929, and to the support given in certain cases by the Greenwich daily averages. But that sort of evidence does not really get us any further. Everyone knows that our weather tends to occur in 'spells'. The essence of the Buchan doctrine is that cold spells and warm spells tend to occur around certain specified dates rather than on other dates. Well then, let us take the best temperature record we can get, start with January 1 and see how often the temperature on that date has been, say, ten degrees or more above normal, and how often it has been ten degrees or more below normal (the 'normal' being the value indicated by an idealized smooth curve drawn through the monthly means). Do this for every day of the year. The job will take some time, but we shall be rewarded in the end with a set of figures from which we can say with reasonable certainty whether or no there is any special tendency towards abnormality during Buchan's periods or during any other periods. The adherents of Buchan seem strangely reluctant to use this very simple and obvious method of establishing their case.

Part I of Mr. Hawke's book is devoted to Buchan, with a very interesting, but not very relevant, chapter on "Weather Lore". Part 2, entitled "Round the Year", contains a series of chapters on the general climatic features of the months and seasons. These chapters are very good of their kind, and contain much curious information such as: "on May 18, 1891, a heavy drifting snowstorm over many hundreds of square miles in England gave holiday-makers the only recorded opportunity for tobogganning on Whit Monday". 